\title{
Feasibility and Safety of a Coaxial Dual-Wavelength Optical Coherence Tomography Apparatus
}

\author{
Luca Cedro $^{a}$ Pascal W. Hasler ${ }^{a, b} \quad$ Christoph Meier ${ }^{c}$ Boris Povazay ${ }^{c}$ \\ Christian Burric Matthias Mooser $^{c}$ Pascal Kaiser ${ }^{d}$ Simon P. Rothenbuehler ${ }^{a}$ b \\ Philipp L. Müller ${ }^{\mathrm{e}}$ Javier Zarranz-Ventura ${ }^{f}$ Catherine Egan $^{\mathrm{e}}$ Adnan Tufaile $^{\mathrm{e}}$ \\ Hendrik P.N. Scholl ${ }^{a, b, d, g}$ Peter M. Maloca ${ }^{a, b, d, e}$ \\ a Department of Ophthalmology, University Hospital Basel, Basel, Switzerland; ${ }^{b}$ OCTlab, Department of \\ Ophthalmology, University Hospital Basel, Basel, Switzerland; ' Institute for Human Centered Engineering (HuCE) \\ optoLab, Bern University of Applied Sciences, Bern, Switzerland; d Institute of Molecular and \\ Clinical Ophthalmology Basel (IOB), Basel, Switzerland; ${ }^{\mathrm{e}}$ Moorfields Eye Hospital NHS Foundation Trust, London, UK; \\ fInstitut Clínic d'Oftalmologia, Hospital Clínic de Barcelona, Barcelona, Spain; 9 Wilmer Eye Institute, \\ Johns Hopkins University, Baltimore, MD, USA
}

\section{Keywords}

Dual-color imaging · Optical coherence tomography, spectral-domain $\cdot$ Retina

\begin{abstract}
Purpose: To evaluate the feasibility and safety of a coaxial dual-wavelength optical coherence tomography (OCT) device (marked as Hydra-OCT). Methods: Healthy participants without ocular pathology underwent retinal imaging using the Hydra-OCT allowing for simultaneous measurement of retinal scanning of 840 and 1,072 nm wavelength. Before and after measurement, best-corrected visual acuity and patients' comfort were assessed. Representative OCT images from both wavelengths were compared by 5 independent graders using a subjective grading scheme. Results: A total of 30 eyes of 30 participants ( 8 females and 22 males) with a mean age of 26.5 years (range from 19 to 55 years) were included. Dual-wavelength image acquisition was made pos-
\end{abstract}

karger@karger.com www.karger.com/ore

Karger $\stackrel{\text { ' }}{5}$

BOPEN ACCESS
(C) 2020 The Author(s)

Published by S. Karger AG, Basel

This is an Open Access article licensed under the Creative Commons Attribution-NonCommercial-4.0 International License (CC BY-NC) (http://www.karger.com/Services/OpenAccessLicense), applicable to the online version of the article only. Usage and distribution for commercial purposes requires written permission. sible in each subject. The participant's effort and comfort assessment using the Hydra-OCT imaging revealed an equivalent value as compared to the commercially available OCT machine. No adverse events were reported, and visual acuity was not altered by the Hydra-OCT. Imaging between the systems was comparable. Conclusions: This study provides evidence for the feasibility and safety of a coaxial dual-wavelength OCT imaging method under real-life conditions. The novel Hydra-OCT imaging device may offer additional insights into the pathology of retinal and choroidal diseases.

(c) 2020 The Author(s)
Published by S. Karger AG, Basel

\section{Introduction}

Optical coherence tomography (OCT) is a noninvasive in vivo imaging technique based on reflected light due to boundaries of different refractive index of the tissue to produce detailed cross-sectional and three-dimen- 
sional images $[1,2]$. Over the past decade, several innovations in the OCT techniques [3-5] have led to significant improvements in the assessment of ophthalmic patients especially for retinal diseases [6]. Thereby, OCT data have been established as an outcome measure for clinical trials as well as for the diagnosis and follow-up of ophthalmic patients [7].

Since 2012 most of the commercially available OCT devices have been line-camera-based spectral-domain OCT (SD-OCT) systems [8] operating with a wavelength of around $800 \mathrm{~nm}$ allowing for a tremendously higher sampling rate and improved signal-to-noise ratio compared to the previously used time domain OCT technique $[9,10]$. To compensate for the lack of deep tissue penetration due to the short wavelength of SD-OCT, the technique of enhanced depth imaging $[11,12]$ utilizing the depth-dependent sensitivity of frequency domain OCT was introduced in order to visualize deeper structures. The wavelength scanning frequency domain technology, swept-source OCT [13] (SS-OCT), operates at a wavelength of $1,070 \mathrm{~nm}$, which ameliorates the depth penetration of the tissue [14] and improves sampling speed for a more comprehensive visualization of the choroid [15, 16]. Longer wavelengths provide refined deeper tissue information [17]. In contrast shorter wavelengths produce higher contrast in superficial tissue.

As the retinal pigment epithelium, Bruch's membrane and the choroid represent a coadjutant functional complex [18], the combination of the advantages of both imaging techniques and respective wavelengths might be aimed for. Up to now, the investigation of ophthalmic patients with both imaging techniques could only be carried out by separate application of at least two OCT devices.

To overcome this drawback, an extended SD-OCT device (Hydra-OCT) was developed that incorporates two different but coaxially aligned wavelengths. We aimed to compare the Hydra-OCT imaging system to a commercially available SD-OCT device with regard to the feasibility, subject comfort and safety in order to allow for future application of the technique in experimental and clinical settings.

\section{Methods}

This study was designed as a prospective, open-label, nonrandomized investigation.

Intended Use

The overall objective of this study was to obtain and assess the feasibility, safety and patient comfort of Hydra-OCT compared to the established SD-OCT. Specific aspects of the Hydra-OCT prototype, such as diagnostic performance and monitoring differences between the devices, were not assessed during this preliminary study.

\section{Subjects}

Healthy volunteers were prospectively recruited for this study and investigated at the Department of Ophthalmology at the University Hospital Basel, Basel, Switzerland. Inclusion criteria were compliant subjects with a minimum age of 18 years or older, German-speaking, clear optic media and without any ocular pathology that were evaluated during a slit lamp examination. Exclusion criteria were coexisting accompanying diseases such as epilepsy, dementia, Parkinson's disease, serious mental health illness, developmental disability or cognitive impairment, general disability that would preclude adequate comprehension for the informed consent, subjects who did not sign informed consent and subjects using electronic medical devices (e.g., hearing aid, cochlear implant, pacemaker, defibrillator).

\section{Sample Size Calculation}

The usability literature indicated that 30 eyes would be an appropriate number [19].

\section{Data Quality Assurance}

For each participant enrolled in the study, an anonymized case report form (CRF) was completed and signed by the primary investigator. Participant identities were coded using a participant identification number. Data analysis and outcome evaluation were performed with anonymized data, and no other blinding procedures were applied.

Conduct of the study was fully documented, and the study data were subsequently verified as required by ISO 14155 and local regulations. Any CRF entries and corrections were performed by the site's staff members and authorized by the primary investigator. The entries were therefore checked by a study nurse and any errors or inconsistencies could then be clarified. At the end of the study, the study nurse collected original, completed and signed CRFs, and their copies were stored on the study site.

\section{Dual-Color Imaging}

The Hydra-OCT (Fig. 1) is constituted of a dual-wavelength coaxial SD-OCT prototype and was developed at the Institute for Human Centered Engineering optoLab, University of Applied Sciences, Biel, Switzerland, as the commercial-grade successor of a device used in a different study in Hong Kong [20], in close collaboration with the Department of Ophthalmology, University Hospital Basel, Basel, Switzerland, and the Institute of Molecular and Clinical Ophthalmology Basel, Basel, Switzerland.

Two superluminescent diodes emitted concurrently, but independently of each other, laser light with a central wavelength of 840 $( \pm 15) \mathrm{nm}$ and $1,072( \pm 20) \mathrm{nm}$, respectively. The bandwidth was 48 $( \pm 12)$ and $103( \pm 15) \mathrm{nm}$, respectively. The lasers were classified as group 1 device according to EN ISO 15004-2:2007 and class 1 laser according to IEC 60825-1. The Hydra-OCT fulfilled all terms and conditions of light hazard of EN ISO 15004-2:2007 according to group 1 and has been reviewed and cleared by independent investigations with regard to laser and electromagnetic safety.

The light beam of the 1,072-nm light source was coupled into the light path of the commercially available OCT device (Spectralis
Cedro et al. 

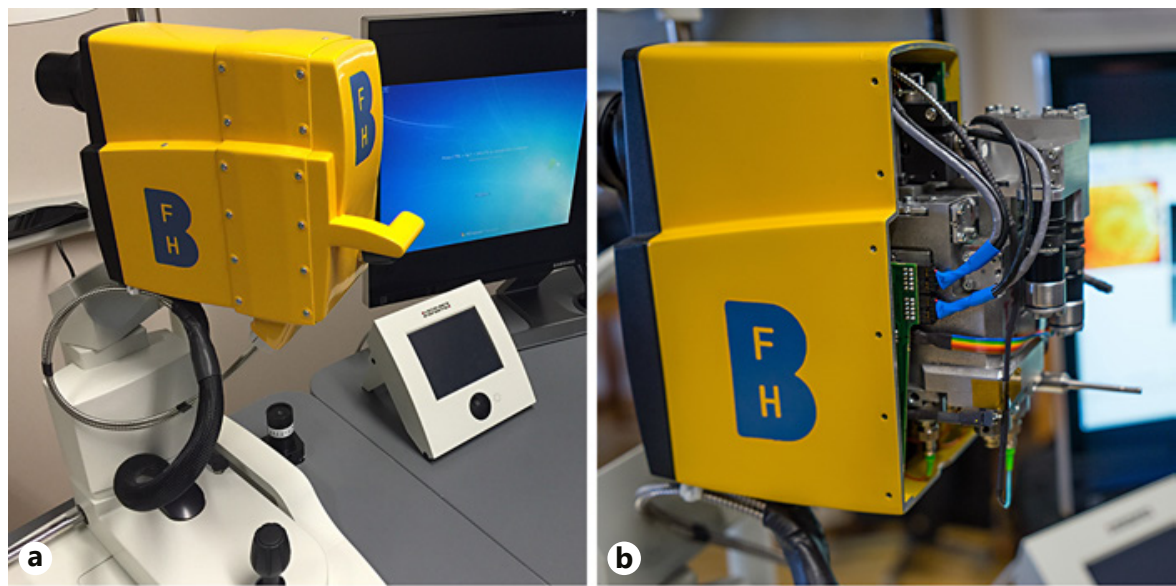

Fig. 1. Representation of the Hydra-OCT with two laser sources enhancing a standard Heidelberg OCT scanner with a 1,072-nm module. a The standard scanner was extended optomechanically with a housing containing the coaxial laser unit. b Interior view of the additional laser unit with feeding light source. c Cross-section OCT of a healthy retina with the standard 840-nm scanner wavelength (Heidelberg Spectralis SD-OCT). d Co-spatiolocalized, additional image information gain by second spectral-domain laser scanning system using a 1,072-nm laser beam.
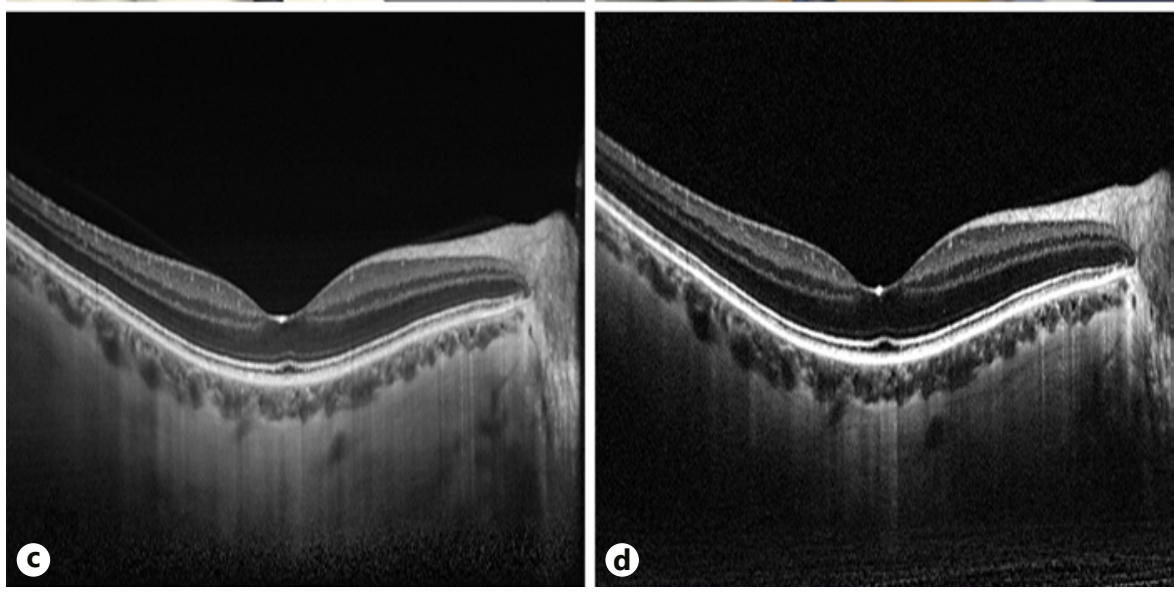

HRA + OCT, Heidelberg Engineering, Heidelberg, Germany). The two OCT beams utilized the same scan geometry with a well-specified retinal offset separation in scan direction of $60 \mu \mathrm{m}$ for eye safety reasons. The backscattered light from the retina was directed to two different spectrometers dedicated to the corresponding wavelengths. The Hydra-OCT had a scan length of $5 \mathrm{~mm}$ and high sample resolution of 400 pixels with an $\mathrm{A}$-scan rate of $15 \mathrm{kHz}$, and averaging of maximal $22 \mathrm{~B}$ scans was possible at this time. Spectralis OCT single-line acquisition had a resolution of 768 pixels, with automatic real-time tracking averaging of $25 \mathrm{~B}$ scans and excluding the technique of enhanced depth imaging (enhanced depth imaging off) which is a recent modification of the standard technique of image acquisition to better display the structural details of the choroid.

\section{Clinical Investigation Safety End Point}

To determine safety performance of the Hydra-OCT, any adverse events, serious adverse events and/or serious adverse device effects were to be collected, fully investigated and reported once they occurred in the course of the study. In addition, best-corrected visual acuity (VA) was measured before and after the HydraOCT imaging using Early Treatment Diabetic Retinopathy Study (ETDRS) charts. In the case of a decrease in individual VA, an additional VA assessment was performed $10 \mathrm{~min}$ after the HydraOCT measurement in order to exclude simple blinding effects.
Concerning participants' comfort during the Hydra-OCT examination, a specified questionnaire was used giving values from 0 to 100 (with 0 being a very uncomfortable investigation and 100 being a very comfortable one, respectively); see online supplementary Table S1 (for all online suppl. material, see www.karger.com/ doi/10.1159/000508751) for the electronic CRF.

Theoretically, an OCT examination can temporarily reduce the VA due to examination side effects such as a laser impact or dry eyes when patients do not blink enough. The safety end point has been formulated as the change in letters logMAR (logarithmic minimum angle of resolution) measured using an ETDRS test chart. One letter on the chart is $0.02 \log$ MAR units. The VA was measured before and after the examination with the Hydra-OCT. If the difference in the VA score decreased by more than $0.1 \mathrm{log}$ MAR (change of more than 5 letters), as measured before and after the OCT imaging, a repeated measurement was taken 10 min later to exclude temporary side effects or simple dry eye problems. In cases where the remeasured VA difference was still greater than 0.1 $\log M A R$, the primary investigator was to examine the eye for adverse events and take appropriate measures, if necessary.

\section{Feasibility and Image Comparability}

For the primary end point, a true/false criterion was explored with regard to the feasibility of the Hydra-OCT, on whether both wavelength scans could be recorded. 
A commercially available SS-OCT device (DRI OCT-1 Atlantis, Topcon, Tokyo, Japan) was used to compare feasibility, subject's comfort and safety. The SS-OCT scan pattern was defined by the manufacturer's software using a single-line B scan of $6 \mathrm{~mm}$ length. There was no subsequent VA assessment after the SS-OCT measurement as the device had already been approved for clinical use and no such changes had been reported till the time of the measurements.

\section{Statistical Analysis Methods}

Frequencies and proportions related to successful measurements were computed, along with the mean value and standard deviation for the duration of the OCT examination performed by using the Hydra-OCT. Before and after each examination, a change in the VA score was calculated for each examined participant. The data were exported as indexed lists in the software package R [21]. Patient comfort during each OCT scanning was recorded and analyzed. Comparisons between pre- and post-VA are assessed using a Wilcoxon signed rank test. A $p$ value $<0.05$ was considered as significant.

\section{Image Comparability between 840- and 1,072-nm Imaging}

After the Hydra-OCT measurement had been performed, the central foveal B-OCT scans were independently reviewed and compared to the standard SD-Spectralis B scan of the corresponding location by 5 blinded medical retina specialists (P.W.H., S.R., P.M., J.Z., C.E.). Since the study only dealt with the feasibility of the new device, a simplified grading was carried out [22]. The results were considered a "comparable" (marked as 1 ) if all the retinal layers and the choroid could be identified in both displayed images from the same eye. In cases when the layers could not be differentiated, the outcome was considered a "fail" (marked as 0). In addition, each image was rated with an individual score and then the total score was calculated for the image category.

A statistical analysis was performed to compare the quality of images acquired by the Hydra-OCT and Spectralis devices. First, the binary assessments of the 5 individual graders were combined into one consensus as follows: if a majority of the graders judged an image pair as "comparable," it was set to "comparable" in the consensus. Otherwise, it was set to "not comparable." The consensus consists of 28 "comparable" and 2 "not comparable" image pairs. Subsequently, we performed a one-sided Fisher's exact test for count data with the null hypothesis that all image pairs are comparable. Fisher's exact test for count data can be used to assess the association between two classifications. In our case, this is the observed classification in "comparable" (28) and "not comparable" (2) image pairs and the hypothesized classification in "comparable" (30) and "not comparable" (0) image pairs.

\section{Results}

\section{Patient Demographics}

A total of 30 eyes from 30 participants (27\% females $[n=8]$ and $73 \%$ males $[n=22])$ who met the inclusion criteria were recruited for OCT retinal examination by both the investigational Hydra-OCT and the reference spectral OCT device. The overall mean age was 26.5 years

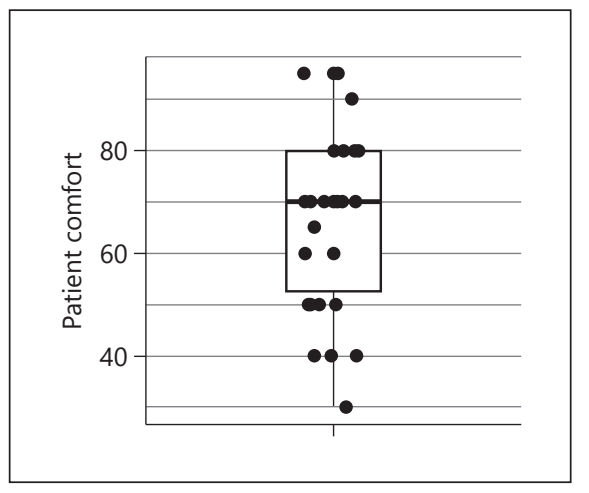

Fig. 2. Box plot of the participant's rating of patient comfort. The rating was performed by assessing the comfort of the investigation on a scale of linear values from 0 to 100 with 0 being a very uncomfortable investigation and 100 being a very comfortable investigation, respectively. The median score was 70 and the interquartile range consisted of a score of 52.5 for the first quartile and 80 for the third quartile, respectively. The minimum score for patient comfort was 30, and the maximum was 95 out of 100 . The results indicate a well-tolerated Hydra-OCT examination that is comparable to a commercially available OCT device.

(range from 19 to 55 years). The mean age of female patients was 28.5 years (range from 21 to 55 years) and of male patients 26.0 years (range from 19 to 55 years, respectively).

\section{Secondary End Point}

The patients' narrative feedback on their comfort during each OCT imaging procedure was documented and summarized in Figure 2. In total, comfort assessments from all 30 patients were obtained. The median and interquartile range of patient comfort was 70.0 (52.5-80.0).

\section{Safety End Point}

One patient showed a VA decline after Hydra-OCT device investigation of one ETDRS line. After $10 \mathrm{~min}$ the VA testing was repeated, and VA returned to normal. Neither safety concerns as defined by VA loss nor adverse effects, serious adverse effects or serious adverse device effects were observed. The descriptive statistics of the comparison of the pre- and postinvestigational VA is summarized in Figure 3.

\section{Intercolor Image Comparability}

The one-sided Fisher's exact test for count data revealed a $p$ value of 0.2458 . That is, our observed classification of "comparable" (28) and "not comparable" (2) image pairs is not significantly different from the hypothe-
58

Ophthalmic Res 2021;64:55-61

DOI: $10.1159 / 000508751$
Cedro et al. 


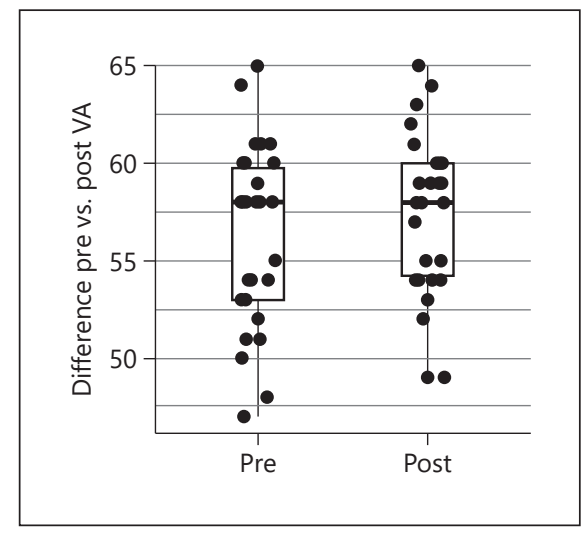

Fig. 3. Box plot of visual acuity (VA) ETDRS score before (pre) and after (post) examination with Hydra-OCT. The assessment was performed using an ETDRS chart. The median score of the measurement of the VA before the examination was 58, and the interquartile range consisted of a score of 53.0 for the first quartile and 59.8 for the third quartile, respectively. The minimum score was 47 , and the maximum was 65 . After the examination, the median score of the measurement of the VA was 58 , and the interquartile range consisted of a score of 54.2 for the first quartile and 60 for the third quartile, respectively. The minimum score was 49 , and the maximum was 65. The exact Wilcoxon signed rank test showed no significant change of VA before compared to after the examination $(p=0.005007)$.

sized classification of "comparable" (30) and "not comparable" (0) image pairs. We found that Spectralis images did not get significantly better judgments than Hydra-OCT images.

\section{Discussion}

OCT has become one of the most important imaging methods for diagnosis and monitoring in a number of diseases such as age-related macular degeneration [11, $23]$, diabetic retinopathy $[24,25]$ and central serous retinopathy [26, 27], among others. Novel insights were mainly driven by technical enhancements such as enhanced depth imaging OCT $[28,29]$, swept-source OCT $[30,31]$ or optical coherence tomography angiography $[32,33]$. Currently, most of these OCT devices are operating using a single wavelength.

The aim of this study was to assess patient comfort and image content equivalence of a recently developed OCT instrument compared to commercially available OCT technologies: The proposed OCT device is based on a commercial OCT device where a Heidelberg Engineering Spectralis (840 $\mathrm{nm}$ wavelength) has been extended to in- sert a second coaxial beam path to introduce a second beam at $1,072 \mathrm{~nm}$. No difference was seen with respect to VA. The subjects reported a comfort at least equivalent to that of a commercially available swept-source OCT device. One patient had transient vision decline of one ETDRS line after the Hydra-OCT measurement. VA returned to normal after $10 \mathrm{~min}$. The patient reported a dry and slightly irritated eye after the measurement which was considered the reason for the vision decline. The performed safety tests did not indicate any patient risks.

In this context, this study demonstrated the successful integration of a novel scanning concept by combining two different wavelength ranges (centered at 840 and $1,072 \mathrm{~nm}$, respectively) in a single OCT device.

The evaluation of the obtained cross-sectional retina images showed a high agreement between the graders who reported that the provided scans were at least similar between the wavelengths. It was interesting to note that the SD-OCT images showed some degree of a blurred image probably due to the averaging of multiple B scans (Fig. 1). Hydra-OCT images, on the other hand, showed a delicate appearance even in the superficial structures such as the optic disk vessels. The quality of deeper areas like choroidal structures were comparable between the two wavelengths.

The ability of light to penetrate scattering tissue is especially depending on the wavelength [34]. Longer wavelengths are able to penetrate more deeply compared to shorter ones $[35,36]$. This allows a more profound investigation of the choroid and even the sclera $[37,38]$.

Furthermore, an examination bringing the advantage of two simultaneous wavelengths may bring more information about the optical properties and the refractive index of a particular component. In this regard, the refractive index could represent an important future parameter of biological tissue or pathological deposits such as drusen $[39,40]$. Changes of such an index have already been reported after refractive surgery [41-44]. For that reason, the Hydra-OCT could contribute new insights into the state of tissue hydration [45], the behavior of multicellular tumor spheroids [46], age-related changes of the lens [47], characteristics of light transmission in Müller glial cells [48] and crystalline cones [49]. A previous report showed that different OCT devices may not be used interchangeably because higher choroidal thickness values were observed in SS-OCT compared to SD-OCT [50]. In this respect, the method presented in this manuscript is consistent since both wavelengths were executed using the identical spectral-domain technology and geometry in one single OCT device. 
A limitation of the study was the small number of subjects. Another weakness would be that only one operator had carried out all measurements and no interoperator variation was evaluated. In addition, no reproducibility of the method was tested because this was not the aim of this first experiment. It is obvious that the grading of the images was simple, since the main goal of the study was to obtain data with regard to safety and feasibility. Another limitation of the study lies in the image grading of the two devices which was assessed by subjective descriptions only. In future studies it will be necessary to address these weaknesses.

In conclusion, the outcome of this study is that the dual wavelength OCT device described is comfortable, safe and provides similar images to an established device.

\section{Acknowledgments}

The authors would like to thank Heidelberg Engineering, Heidelberg, Germany, for their technical support.

\section{Statement of Ethics}

Approval from the local Swiss ethics committee (EKNZ: 201601435) and Swissmedic (reference No.: 10000317) and written informed consent were obtained from all subjects. The study was in adherence with the Declaration of Helsinki and in accordance with good clinical practice.

\section{Disclosure Statement}

The authors declare that there is no conflict of interest regarding the publication of this paper.

\section{Funding Sources}

The study was supported by a grant from Blueye Vision Tech $\mathrm{GmbH}$, Luzern, Switzerland, Hirslanden Klinik, Luzern, Switzerland, B. Braun Medical AG, Sempach, Switzerland, Verein zur Förderung der Weiterbildung in der Augenheilkunde, the German Research Foundation (grant MU4279/2-1 to P.L.M.) and the Swiss National Science Foundation (grant 320030_146021). No sponsor or funding agency had any involvement in the design, collection, analysis and interpretation of the data, manuscript writing and the decision to submit the manuscript for publication.

\section{Author Contributions}

L.C., B.P., P.W.H., C.M., C.B., M.M., C.E., A.T., H.P.N.S., P.M.M.: conceptualization, methodology, software, validation, formal analysis, investigation, resources, data curation, writing, original draft preparation, writing review and editing, visualization, project administration.

P.K., S.R., P.L.M., J.Z.V.: methodology, software, validation, formal analysis, data curation, writing, original draft preparation, writing review and editing.

\section{References}

1 Puliafito CA, Hee MR, Lin CP, Reichel E, Schuman JS, Duker JS, et al. Imaging of macular diseases with optical coherence tomography. Ophthalmology. 1995 Feb;102(2):21729.

2 Hee MR, Izatt JA, Swanson EA, Huang D, Schuman JS, Lin CP, et al. Optical coherence tomography of the human retina. Arch Ophthalmol. 1995;113(3):325-32.

3 Chen TC, Cense B, Pierce MC, Nassif N, Park $\mathrm{BH}, \mathrm{Yun} \mathrm{SH}$, et al. Spectral domain optical coherence tomography: ultra-high speed, ultrahigh resolution ophthalmic imaging. Arch Ophthalmol. 2005;123(12):1715-20.

4 Drexler W, Fujimoto JG. State-of-the-art retinal optical coherence tomography. Prog Retin Eye Res. 2008 Jan;27(1):45-88.

5 Anger EM, Unterhuber A, Hermann B, Sattmann H, Schubert C, Morgan JE, et al. Ultrahigh resolution optical coherence tomography of the monkey fovea. Identification of retinal sublayers by correlation with semithin histology sections. Exp Eye Res. 2004 Jun; 78(6):1117-25.
6 Sakata LM, Deleon-Ortega J, Sakata V, Girkin CA. Optical coherence tomography of the retina and optic nerve - a review. Clin Exp Ophthalmol. 2009 Jan;37(1):90-9.

7 Fujimoto J, Huang D. Foreword: 25 years of optical coherence tomography. Invest Ophthalmol Vis Sci. 2016;57(9):OCTi-OCTii.

8 Kałuzny JJ, Szkulmowska A, Bajraszewski T, Szkulmowski M, Kałuzny BJ, Gorczyńska I, et al. Retinal imaging by spectral optical coherence tomography. Eur J Ophthalmol. 2007 Mar-Apr;17(2):238-45.

9 Cense B, Nassif N, Chen T, Pierce M, Yun SH, Park B, et al. Ultrahigh-resolution high-speed retinal imaging using spectral-domain optical coherence tomography. Opt Express. 2004 May;12(11):2435-47.

10 Fernández EJ, Povazay B, Hermann B, Unterhuber A, Sattmann H, Prieto PM, et al. Threedimensional adaptive optics ultrahigh-resolution optical coherence tomography using a liquid crystal spatial light modulator. Vision Res. 2005 Dec;45(28):3432-44.
11 Spaide RF. Enhanced depth imaging optical coherence tomography of retinal pigment epithelial detachment in age-related macular degeneration. Am J Ophthalmol. 2009 Apr; 147(4):644-52.

12 Spaide RF, Koizumi H, Pozzoni MC. Enhanced depth imaging spectral-domain optical coherence tomography. Am J Ophthalmol. 2008 Oct;146(4):496-500.

13 Choma M, Sarunic M, Yang C, Izatt J. Sensitivity advantage of swept source and Fourier domain optical coherence tomography. Opt Express. 2003 Sep;11(18):2183-9.

14 Copete S, Flores-Moreno I, Montero JA, Duker JS, Ruiz-Moreno JM. Direct comparison of spectral-domain and swept-source OCT in the measurement of choroidal thickness in normal eyes. Br J Ophthalmol. 2014 Mar; 98(3):334-8.

15 Tan CS, Ngo WK, Cheong KX. Comparison of choroidal thicknesses using swept source and spectral domain optical coherence tomography in diseased and normal eyes. Br J Ophthalmol. 2015 Mar;99(3):354-8. 
16 Zafar S, Siddiqui MR, Shahzad R. Comparison of choroidal thickness measurements between spectral-domain OCT and sweptsource OCT in normal and diseased eyes. Clin Ophthalmol. 2016;10:2271-6.

17 Unterhuber A, Povazay B, Hermann B, Sattmann H, Chavez-Pirson A, Drexler W. In vivo retinal optical coherence tomography at $1,040 \mathrm{~nm}$ - enhanced penetration into the choroid. Opt Express. 2005 May;13(9):32528

18 Saint-Geniez M, Kurihara T, Sekiyama E, Maldonado AE, D'Amore PA. An essential role for RPE-derived soluble VEGF in the maintenance of the choriocapillaris. Proceedings of the National Academy of Sciences of the United States of America. 2009;106(44): 18751-6. Epub 2009/10/21. doi: . PubMed PMID: 19841260; PubMed Central PMCID: PMCPMC2774033.

19 Faulkner L. Beyond the five-user assumption: benefits of increased sample sizes in usability testing. Behav Res Methods Instrum Comput. 2003 Aug;35(3):379-83.

20 Ronchetti T, Jud C, Maloca PM, Orgul S, Giger AT, Meier C, et al. Statistical framework for validation without ground truth of choroidal thickness changes detection. PLoS One. 2019;14(6):e0218776.

21 Team RC. R: A language and environment for statistical computing. 2014.

22 Huang Y, Gangaputra S, Lee KE, Narkar AR, Klein R, Klein BE, et al. Signal quality assessment of retinal optical coherence tomography images. Invest Ophthalmol Vis Sci. 2012; 53(4):2133-41.

23 Holz FG, Tadayoni R, Beatty S, Berger A, Cereda MG, Cortez R, et al. Multi-country real-life experience of anti-vascular endothelial growth factor therapy for wet age-related macular degeneration. Br J Ophthalmol. 2015;99(2):220-6.

24 Wang YT, Tadarati M, Wolfson Y, Bressler SB, Bressler NM. Comparison of Prevalence of Diabetic Macular Edema Based on Monocular Fundus Photography vs Optical Coherence Tomography. JAMA Ophthalmol. 2016 Feb;134(2):222-8

25 Gerendas BS, Bogunovic H, Sadeghipour A, Schlegl T, Langs G, Waldstein SM, et al. Computational image analysis for prognosis determination in DME. Vision Res. 2017 Oct; 139: 204-10.

26 Chaikitmongkol V, Kong J, Khunsongkiet P, Patikulsila D, Sachdeva M, Chavengsaksongkram P, et al. Sensitivity and Specificity of Potential Diagnostic Features Detected Using Fundus Photography, Optical Coherence Tomography, and Fluorescein Angiography for Polypoidal Choroidal Vasculopathy. JAMA Ophthalmol. 2019 Jun;137(6):661-7.
27 Hanumunthadu D, van Dijk EHC, Dumpala S, Rajesh B, Jabeen A, Jabeen A, et al. Evaluation of choroidal layer thickness in central serous chorioretinopathy. J Ophthalmic Vis Res. 2019;14(2):164-70.

28 Imamura Y, Iida T, Maruko I, Zweifel SA Spaide RF. Enhanced depth imaging optical coherence tomography of the sclera in domeshaped macula. Am J Ophthalmol. 2011 Feb; 151(2):297-302.

29 Margolis R, Spaide RF. A pilot study of enhanced depth imaging optical coherence tomography of the choroid in normal eyes. Am J Ophthalmol. 2009 May;147(5):811-5.

30 Parravano M, Borrelli E, Sacconi R, Costanzo E, Marchese A, Manca D, et al. A comparison among different automatically segmented slabs to assess neovascular AMD using swept source OCT angiography. Transl Vis Sci Technol. 2019;8(2):8

31 Wang JC, Lains I, Silverman RF, Sobrin L, Vavvas DG, Miller JW, et al. Visualization of choriocapillaris and choroidal vasculature in healthy eyes with en face swept-source optical coherence tomography versus angiography. Transl Vis Sci Technol. 2018;7(6):25.

32 Alibhai AY, De Pretto LR, Moult EM, Or C, Arya M, McGowan M, et al. Quantification of retinal capillary nonperfusion in diabetics using wide-field optical coherence tomography angiography. Retina. 2020 Mar;40(3):412-20.

33 Arya M, Rashad R, Sorour O, Moult EM, Fujimoto JG, Waheed NK. Optical coherence tomography angiography (OCTA) flow speed mapping technology for retinal diseases. Expert Rev Med Devices. 2018 Dec;15(12):87582.

34 Adhi M, Liu JJ, Qavi AH, Grulkowski I, Fujimoto JG, Duker JS. Enhanced visualization of the choroido-scleral interface using sweptsource OCT. Ophthalmic Surg Lasers Imaging Retina. 2013 Nov-Dec;44(6 Suppl):S40-2.

35 Kodach VM, Kalkman J, Faber DJ, van Leeuwen TG. Quantitative comparison of the OCT imaging depth at $1,300 \mathrm{~nm}$ and $1,600 \mathrm{~nm}$. Biomed Optics Express. 2010;1(1):176-85.

36 Povazay B, Bizheva K, Hermann B, Unterhuber A, Sattmann H, Fercher A, et al. Enhanced visualization of choroidal vessels using ultrahigh resolution ophthalmic OCT at 1,050 nm. Opt Express. 2003 Aug;11(17):1980-6.

37 Barteselli G, Bartsch DU, El-Emam S, Gomez ML, Chhablani J, Lee SN, et al. Combined depth imaging technique on spectral-domain optical coherence tomography. Am J Ophthalmol. 2013;155(4):727-32.

38 Barteselli G, Bartsch DU, Freeman WR. Combined depth imaging using optical coherence tomography as a novel imaging technique to visualize vitreoretinal choroidal structures. Retina. 2013;33(1):247-8.
39 Ahlers C, Gotzinger E, Pircher M, Golbaz I, Prager F, Schutze C, et al. Imaging of the retinal pigment epithelium in age-related macular degeneration using polarization-sensitive optical coherence tomography. Invest Ophthalmol Vis Sci. 2010;51(4):2149-57.

40 Schlanitz FG, Sacu S, Baumann B, Bolz M, Platzer M, Pircher M, et al. Identification of drusen characteristics in age-related macular degeneration by polarization-sensitive optical coherence tomography. Am J Ophthalmol. 2015;160(2):335-44.e1.

41 Tearney GJ, Brezinski ME, Southern JF, Bouma BE, Hee MR, Fujimoto JG. Determination of the refractive index of highly scattering human tissue by optical coherence tomography. Opt Lett. 1995 Nov;20(21):2258.

42 Wang Z, Tangella K, Balla A, Popescu G. Tissue refractive index as marker of disease. J Biomed Optics. 2011;16(11):116017.

43 Patel S, Alió JL, Artola A. Changes in the refractive index of the human corneal stroma during laser in situ keratomileusis. Effects of exposure time and method used to create the flap. J Cataract Refract Surg. 2008 Jul;34(7): 1077-82.

44 Patel S, Alió JL, Pérez-Santonja JJ. Refractive index change in bovine and human corneal stroma before and after lasik: a study of untreated and re-treated corneas implicating stromal hydration. Invest Ophthalmol Vis Sci. 2004 Oct;45(10):3523-30.

45 Kim YL, Walsh JT Jr, Goldstick TK, Glucksberg MR. Variation of corneal refractive index with hydration. Phys Med Biol. 2004 Mar; 49(5):859-68.

46 Sharma M, Verma Y, Rao KD, Nair R, Gupta PK. Imaging growth dynamics of tumour spheroids using optical coherence tomography. Biotechnol Lett. 2007 Feb;29(2):273-8.

47 Chakraborty R, Lacy KD, Tan CC, Park HN, Pardue MT. Refractive index measurement of the mouse crystalline lens using optical coherence tomography. Exp Eye Res. 2014;125:6270.

48 Agte S, Savvinov A, Karl A, Zayas-Santiago A Ulbricht E, Makarov VI, et al. Müller glial cells contribute to dim light vision in the spectacled caiman (Caiman crocodilus fuscus): analysis of retinal light transmission. Exp Eye Res. 2018 Aug; 173:91-108.

49 Gál J, Miyazaki T, Meyer-Rochow VB. Computational determination of refractive index distribution in the crystalline cones of the compound eye of Antarctic krill (Euphausia superba). J Theor Biol. 2007 Jan;244(2):31825.

50 Matsuo Y, Sakamoto T, Yamashita T, Tomita M, Shirasawa M, Terasaki H. Comparisons of choroidal thickness of normal eyes obtained by two different spectral-domain OCT instruments and one swept-source OCT instrument. Invest Ophthalmol Vis Sci. 2013 Nov; 54(12):7630-6. 